\title{
Synthesis, biological evaluation and mechanism studies of matrine derivatives as anticancer agents
}

\author{
LIHE JIANG $^{12^{*}}$, LICHUAN WU $^{1 *}$, FANGFANG YANG $^{1 *}$, NADIN ALMOSNID $^{2}$, XU LIU ${ }^{1}$, \\ JUN JIANG $^{1}$, ELLIOT ALTMAN ${ }^{2}$, LISHENG WANG ${ }^{1}$ and YING GAO ${ }^{2}$ \\ ${ }^{1}$ The Center for Drug Screening and Research, School of Chemistry and Chemical Engineering, Guangxi University, \\ Nanning, Guangxi 530004, P.R. China; ${ }^{2}$ Department of Biology, Tennessee Center for Botanical Medicine Research, \\ Middle Tennessee State University, Murfreesboro, TN 37132, USA
}

Received May 12, 2016; Accepted May 11, 2017

DOI: $10.3892 / \mathrm{ol} .2017 .6475$

\begin{abstract}
A total of five matrine derivatives were synthesized and evaluated for their anti-proliferation activity using a panel of four human cancer cell lines, including A549 lung, BT20 breast, MCF-7 breast and U2OS osteosarcoma cells. The YF3-5, YF3-7 and YF3-9, three novel compounds, demonstrated increased anti-proliferation activity compared with matrine, of which YF3-5 revealed the strongest anti-proliferation activity with a half-maximal inhibitory concentration value of 15.49-16.67 $\mu \mathrm{M}$ against the four human cancer cell lines. The anti-proliferation mechanism underlying YF3-5 was investigated in the A549 human lung cancer cell line and the results demonstrated that YF3-5 exerted its anti-proliferation activity through the induction of apoptosis and oxidative stress, in addition to arresting the cell cycle at the $G_{1}$ phase in a dose-dependent manner.
\end{abstract}

\section{Introduction}

Lung cancer is the primary cause of cancer-associated mortalities and is ranked the highest in males and second highest in females for mortality and morbidity rates globally (1). Non-small cell lung cancer (NSCLC), which constitutes $80-85 \%$ of lung cancer cases, remains an aggressive type of

Correspondence to: Professor Lisheng Wang, The Center for Drug Screening and Research, School of Chemistry and Chemical Engineering, Guangxi University, 100 Daxue East Road, Nanning, Guangxi 530004, P.R. China

E-mail:wmmglatw@126.com

Dr Ying Gao, Department of Biology, Tennessee Center for Botanical Medicine Research, Middle Tennessee State University, 1301 East Main Street, Murfreesboro, TN 37132, USA

E-mail: ying.gao@mtsu.edu

*Contributed equally

Key words: matrine derivatives, anti-proliferation, cell cycle, apoptosis, oxidative stress lung cancer that is associated with poor patient survival (2). Currently, chemotherapy has reached a plateau of effectiveness in improving patient survival, and it is the mainstay of treatment regimens and new drugs, including erlotinib and gefitinib, that they will eventually fail due to drug resistance $(3,4)$; therefore, novel approaches and drugs are urgently required in order to improve the prognosis of patients with lung cancer.

Natural compounds remain a predominant source for anticancer drug development. A total of $47 \%$ of the 155 anticancer drugs approved from 1950-2006 were natural products or directly derived from them (5). Matrine $\left(\mathrm{C}_{15} \mathrm{H}_{24} \mathrm{~N}_{2} \mathrm{O}\right)$ is the major alkaloid component identified in Sophora alopecuroides roots, which are widely utilized in traditional Chinese medicine and have a wide range of pharmacological effects, including anti-cardiac, anti-arrhythmic, anti-bacterial, anti-asthma, anti-diuretic, immune suppressive and anti-inflammatory activities (6-9). It has also been reported that matrine possesses antitumor activities in vitro and in vivo (10-13). The mechanisms underlying matrine's antitumor activities include the inhibition of cell proliferation and the induction of apoptosis (14-16). However, the low water solubility, bioavailability and bioactivity of matrine, coupled with its considerable side effects, which include general toxicity to the central nervous system, have limited its utility as a therapeutic drug $(17,18)$. Therefore, studies have been focusing on developing derivatives and analogues of matrine by total synthesis or structural modifications in order to improve its activity and bioavailability (19-21).

A previous study demonstrated that the amide bond may be required for the antitumor activities of matrine as following opening of the D-ring and breaking of the amide bond, the anti-proliferative activities of matrine are lost (22). Based on the potential positions for modifying matrine, the present study designed, synthesized and characterized five matrine derivatives for their anti-proliferation potential.

\section{Materials and methods}

Reagents and cell culture. Matrine (purity, 98\%) was purchased from Shaanxi Undersun Biomedtech Co., Ltd., Xian, China. Matrine was dissolved in PBS to dilute to various concentrations $(50,100,200,400,600,800 \mu \mathrm{M})$ at the time of adding 
to cells. The derivatives were dissolved in dimethyl sulphoxide (DMSO) to make a stock solution at $100 \mathrm{mM}$. MTT was purchased from Sigma-Aldrich (Merck KGaA, Darmstadt, Germany). The apoptosis detection kit (Flowcellect ${ }^{\mathrm{TM}}$ Annexin Red kit) was purchased from EMD Millipore (Billerica, MA, USA). The A549 human lung cancer cells, BT-20 human breast cancer cells, MCF-7 human breast cancer cells and U20S human osteosarcoma cells were obtained from the American Type Culture Collection (Manassas, VA, USA). Cells were cultured in Dulbecco's modified Eagle's medium high-glucose (Invitrogen; Thermo Fisher Scientific, Inc., Waltham, MA, USA) supplemented with $10 \%$ fetal bovine serum (Gibco; Thermo Fisher Scientific, Inc.) and $1 \%$ penicillin-streptomycin at $37^{\circ} \mathrm{C}$ in an humidified atmosphere containing $95 \%$ air and $5 \% \mathrm{CO}_{2}$.

General procedure for the preparation of matrine derivatives. A total of $6 \mathrm{mmol}(3.0 \mathrm{ml})$ lithium diisopropylamide [LDA; $2.0 \mathrm{~mol} / \mathrm{l}$ in tetrahydrofuran (THF)] was added to $20 \mathrm{ml}$ anhydrous THF in dried three-necked bottle under a dry nitrogen atmosphere and the solution was cooled to $0^{\circ} \mathrm{C}$. Subsequently, $5 \mathrm{mmol}(1.24 \mathrm{~g})$ matrine dissolved in anhydrous THF was added dropwise and the solution was stirred for $30 \mathrm{~min}$ at $0^{\circ} \mathrm{C}$. A total of $10 \mathrm{mmol}$ of the corresponding reagent (3-methylbenzyl bromide, 2-naphthaldehyde, 6-methoxy-2-naphthdehyde and methyl 6-bromo-2-naphthoate (all from Ameresco, Inc., Framingham, MA, USA) was then added into the solution and stirred for another $3 \mathrm{~h}$ at room temperature. Subsequently, the reaction was inhibited by adding $10 \mathrm{ml}$ saturated $\mathrm{NH}_{4} \mathrm{Cl}$. Finally the solution was extracted using dichloromethane $(15 \mathrm{ml}, 3 \mathrm{X})$ at room temperature for $30 \mathrm{~min}$, washed with saturated brine, dried over $\mathrm{Na}_{2} \mathrm{SO}_{4}$ and concentrated (under -0.1 MPa pressure) at room temperature, providing the corresponding final products. For YF3-3, $50 \mathrm{mg}(0.2 \mathrm{mmol})$ matrine was dissolved in $10 \mathrm{ml}$ of ether and $1 \mathrm{ml}(16 \mathrm{mmol})$ of $\mathrm{CH}_{3} \mathrm{I}$ was added. The mixture was allowed to stand overnight at room temperature and no precipitate of methiodide was observed. The mixture was refluxed and a slow precipitate of methiodide was observed after $\sim 3 \mathrm{~h}$. Refluxing was continued for a further $7 \mathrm{~h}$, the reaction mixture was evaporated and the residue was recrystallizated from $\mathrm{C}_{2} \mathrm{H}_{5} \mathrm{OH}$ to provide $36 \mathrm{mg}$ of needles.

Cell proliferation, apoptosis and cell cycle assay. The experiments of cell proliferation, apoptosis and cell cycle assay were performed as previously described (23).

An MTT assay was performed to measure proliferation. Cells (BT-20, A549, MCF-7 and U20S) were seeded in 96-well plates at a density of 4,000 cells/well and incubated for $24 \mathrm{~h}$ at $37^{\circ} \mathrm{C}$ prior to the assay.

For cell cycle analysis, A549 cells were seeded in 12-well plates at a density of $1 \times 10^{5}$ cells per well and incubated for $24 \mathrm{~h}$ at $37^{\circ} \mathrm{C}$. Then YF3-5 $(12.5,25$ or $50 \mu \mathrm{M})$ was added. Following a further $24 \mathrm{~h}$ at $37^{\circ} \mathrm{C}$, cells were harvested and fixed with $75 \%$ ethanol for $2 \mathrm{~h}$, stained with propidium iodide and analyzed with flow cytometry.

For the apoptosis assay, A549 cells were seeded in 6-well plates at the density of $3 \times 10^{5}$ cells per well and incubated for $24 \mathrm{~h}$ at $37^{\circ} \mathrm{C}$. Then YF3-5 $(25,50$ or $100 \mu \mathrm{M})$ was added. Following a further $24 \mathrm{~h}$ at $37^{\circ} \mathrm{C}$, cells were stained with Annexin V-fluorescein isothiocyanate (FITC)/7-AAD and analyzed with flow cytometry.
Oxidative stress assay. The effect of YF3-5 on the reactive oxygen species (ROS) formation in A549 cells was determined by an oxidative stress assay. Briefly, A549 cells at $80 \%$ confluency were treated with differing concentration of YF3-5 (100, 50 and $25 \mu \mathrm{M}$ ) for $23.5 \mathrm{~h}$ at room temperature. Subsequently, $50 \mu \mathrm{l}$ of pre-warmed staining solution containing dihydroethidium (DHE) and Hoechst dye were added to the wells and incubated at $37^{\circ} \mathrm{C}$ in $5 \% \mathrm{CO}_{2}$ for $30 \mathrm{~min}$. The cells were then fixed with formaldehyde at room temperature for $2 \mathrm{~h}$ and the nuclei intensity of ethidium, a product of DHE oxidation, was determined using the Array Scan HCS reader (Thermo Fisher Scientific, Inc.). In each well, $\geq 400$ cells were analyzed.

Molecular docking assay and ClogP calculation. The computational docking test was performed using Molecular Operating Environment 2008.10 (Chemical Computing Group Inc., Montreal, Canada) as previously described (24). Briefly, an $\mathrm{X}$-ray crystallography structures of cyclin-dependent kinase (CDK)2 [Research Collaboration for Structural Bioinformatics Protein Data Bank (PDB) identity (ID): 2VV9], CDK4 (PDB ID: 2V9F), CDK6 (PDB ID: 1JOW), cyclin D1 (PDB ID: 2W99) and cyclin E (PDB ID: 1W98) and the corresponding ligand were downloaded from PDB (http://www.rcsb.org). The protein and compound YF3-5 were optimized to retain a low energy state prior to docking. Docking score was refined by forcefield and evaluated using the London $\mathrm{dG}$ scoring method. For the calculation of ClogP, ChemDraw software version 14.0 was used, with default settings (PerkinElmer, Inc., Waltham, MA, USA).

Western blot assay. A549cells ( $3 \times 10^{5}$ per well) were seeded in 6-well culture plates, treated with 25 or $50 \mu \mathrm{M}$ YF3-5 for 12 and $24 \mathrm{~h}$ at $37^{\circ} \mathrm{C}$ and lysed in radioimmunoprecipitation assay lysis buffer (Beyotime Institute of Biotechnology, Haimen, China) supplemented with a protease inhibitor cocktail and phenylmethane sulfonyl fluoride. Whole-cell lysates were collected by centrifugation at $12,000 \mathrm{x} \mathrm{g}$ for $10 \mathrm{~min}$ at $37^{\circ} \mathrm{C}$. The protein concentration was measured with the BCA Protein Assay kit (Pierce; Thermo Fisher Scientific, Inc.). Lysates containing $30 \mu \mathrm{g}$ of protein were separated by SDS-PAGE (8-15\%) and transferred to nitrocellulose membranes (EMD Millipore). Subsequently, blocking was performed using $5 \%$ dried skimmed milk for $1 \mathrm{~h}$ at room temperature. The membrane was then probed with antibodies against $\mathrm{Rb}$ (cat. no. 9309; 1:1,000; CST Biological Reagents Company Ltd., Shangai, China), phosphorylated Rb (cat. no. 8516; 1:1,000; CST Biological Reagents Company Ltd.) and $\beta$-actin (cat. no. 3700; 1:1,000; CST Biological Reagents Company Ltd.) for $2 \mathrm{~h}$ at room temperature following incubation with relative secondary antibodies (rabbit anti-mouse mAb-HRP conjugate; cat. no. 58802 and mouse anti-rabbit mAb-HRP conjugate; cat. no. 5127; 1:10,000; CST Biological Reagents Company Ltd.) for $2 \mathrm{~h}$ at room temperature and detected using a chemiluminescence substrate (Cell Signaling Technology, Inc., Danvers, MA, USA).

Statistical analysis. Data are presented as the mean \pm standard deviation. Differences between two groups were compared using the Student's t-tests. All experiments were repeated $\geq 3$ times. $\mathrm{P}<0.05$ was considered to indicate a statistically significant difference. 
A<smiles></smiles><smiles>[R]C(=C)C</smiles>

RW 23<smiles>O=C1CCCC2C3CCCN4CCCC(CN12)C34</smiles><smiles>[R]C(C)C</smiles><smiles>COc1ccc(C(O)C2CCC3C(=O)N4CC5CCCN4CCCC3C52)cc1</smiles>

YF 3-9<smiles>O=C1C(O)=C2CCC3C4CCCN5CCCC(CN1C5)C243</smiles>

YF 3-5

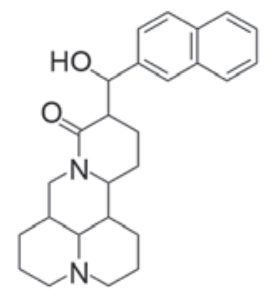

YF 3-7

Figure 1. Synthesis of matrine derivatives. (A) Synthesis of YF3-5, YF3-7, YF3-9 and RW-23. Reagents and condition: Litium diisopropylamide, anhydrous tetrahydrofuran, N2, 0, room temperature, 3 h. RW 23 R1=3-methylbenzyl bromide; YF 3-5 R2=methyl 6-bromo-2-naphthoate; YF 3-9 R3=6-methoxy-2-naphthdehyde; YF 3-7 R4=2-naphthaldehyde. (B) Synthesis of YF3-3. Reagents and condition: ether, methiodide, reflux $7 \mathrm{~h}$.

\section{Results}

Synthesis of five matrine derivatives. Four matrine derivatives were synthesized, as presented in Fig. 1A and characterized in Table I. Derivatives of matrine were prepared by allowing matrine to react with 3-methylbenzyl bromide, 2-naphthaldehyde, 6-methoxy-2-naphthdehyde and methyl 6-bromo-2-naphthoate, respectively, in the presence of LDA and nitrogen atmosphere at $0^{\circ} \mathrm{C}$ for $30 \mathrm{~min}$, then at room temperature for $3 \mathrm{~h}$. For compound YF3-3, matrine was dissolved in diethyl ether and reacted with $\mathrm{CH}_{3} \mathrm{I}$ (Fig. 1B).

Characterization of YF3-3:4-methyl-10-oxotetradecahydro1H, 5H-dipyrido [2,1-f.3',2'-ij][1,6] naphthyridin-4-ium iodide. The crude mixture obtained was purified by recrystallation with ethanol and acetone; the appearance of the compound was yellow crystal. The melting point $(\mathrm{mp})$ was 268.1-270. $2^{\circ} \mathrm{C}$ and the yield was $46 \%$.

Characterization of YF3-5:(Z)-11-((6-bromonaphthalen-2-yl) (hydroxy) methylene) dodecahydro-1H,5H, 10H-dipyrido [2,1-f:3',2',1'-ij][1,6] naphthyridin-10-one. The crude mixture obtained was purified by column chromatography eluting with petroleum ether/ethyl acetate (1:1), the appearance of the compound was white powder. The $\mathrm{mp}$ was $165.1-166.8^{\circ} \mathrm{C}$ and the yield was $56 \%$.

Characterization of YF3-7:11-(hydroxy (naphthalen-2-yl) methyl) dodecahydro- $1 \mathrm{H}, 5 \mathrm{H}, 10 \mathrm{H}$-dipyrido[2,1-f:3',2',1'-ij] $[1,6]$ naphthyridin-10-one. The crude mixture obtained was purified by column chromatography eluting with petroleum ether/ethyl acetate (100:80), the appearance of the compound was white powder. The $\mathrm{mp}$ was $179.6-189.5^{\circ} \mathrm{C}$ and the yield was $51 \%$.
Characterization of YF3-9:11-(hydroxy (6-methoxynaphthalen-2-yl)methyl)dodecahydro- $1 \mathrm{H}, 5 \mathrm{H}, 10 \mathrm{H}$-dipyrido [2,1-f:3',2',1'-ij][1,6]naphthyridin-10-one. The crude mixture obtained was purified by column chromatography eluting with ethyl acetate/methanol (10:1), the appearance of the compound was white powder. The $\mathrm{mp}$ was $174.0-174.3^{\circ} \mathrm{C}$ and the yield was $63 \%$.

Characterization of $R W$-23:11-(3-methylbenzyl) dodecahydr $o$ - $1 H, 5 H, 10 H$-dipyrido[2,1-f:3', $2^{\prime}, 1^{\prime}-$-ij] [1,6] naphthyridin10-one. The crude mixture obtained was purified by column chromatography eluting with petroleum ether/ethyl acetate (1:10), the compound was a yellow, thick liquid; the hydrochloride form was an orange solid. The $\mathrm{mp}$ was $60.5-62.3^{\circ} \mathrm{C}$ and the yield was $57 \%$.

Anti-proliferation activities of five matrine derivatives. The anti-proliferation effects of the matrine derivatives were analyzed in A549 lung, BT-20 breast, MCF-7 breast and U20S osteosarcoma cancer cells using an MTT assay for $48 \mathrm{~h}$. As presented in Table II, all compounds exhibited anti-proliferation effects on the cancer cells. The growth inhibition activity of matrine was moderate in the four cancer cell lines, whereas YF3-5, YF3-7 and YF3-9 significantly inhibited growth in comparison with matrine. YF3-5 exhibited the most potent growth inhibition of all the cancer cell lines used in this model. The anti-proliferation activity of YF3-5 [half-maximal inhibitory concentration $\left(\mathrm{IC}_{50}\right)$ ranging from $\left.15.49-16.67 \mu \mathrm{M}\right]$ was 9-29 times more potent compared with that of matrine $\left(\mathrm{IC}_{50}\right.$ ranging from $152.00-452.30 \mu \mathrm{M})$. It was suggested that the improved anticancer activities of compounds were consistent with their relative CLogP values determined by ChemDraw software. Compound YF3-5 had the highest CLogP value, which indicated that the structure modification of YF3-5 may 


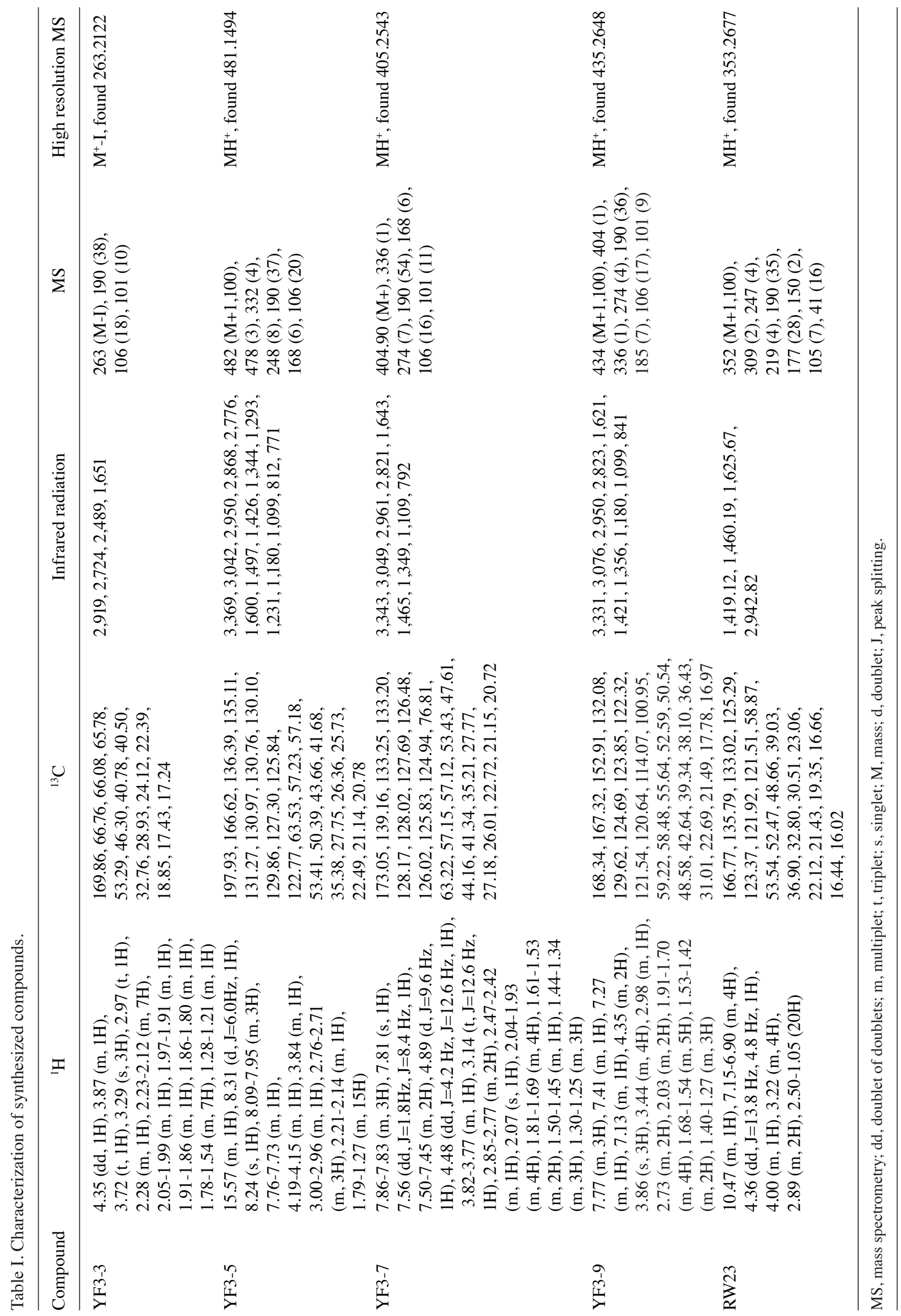


increase its lipophilicity and increase cell solubility. As there is a requirement for novel treatment options for NSCLC, and as compound YF3-5 was the most potent growth inhibitor against cancer cells amongst the synthesized compounds that were analyzed, the present study further investigated the efficacy and cytotoxic mechanisms underlying YF3-5 using the A549 cell line.

Derivative YF3-5 arrests cell cycle in the $G_{1}$ phase in A549 lung cancer cells. To determine whether the cytotoxicity of YF3-5 against A549cells involved cell cycle arrest, the present study examined the cell cycle distribution of A549 cells treated with YF3-5 using propidium iodide staining and flow cytometry analysis. As presented in Fig. 2, after a 24-h treatment with $12.5,25$ or $50 \mu \mathrm{M}$ YF3-5, YF3-5 arrested the cell cycle of A549 cells at the $\mathrm{G}_{1}$ phase in a dose-dependent manner. YF3-5 increased the percentage of cells at the $\mathrm{G}_{1}$ phase from $38 \%$ (vehicle control) to $69 \%(\mathrm{P}<0.05)$ and $91 \%(\mathrm{P}<0.01)$ at concentrations of 25 and $50 \mu \mathrm{M}$, respectively (Fig. 2A-C). To further investigate the underlying mechanism of YF3-5-induced $\mathrm{G}_{1}$ cell cycle arrest, the present study performed molecular docking of YF3-5 with $\mathrm{G}_{1}$ regulators (25). Molecular docking analysis of the YF3-5 complex with CDKs, cyclin E and cyclin D1 structures (26) was performed and the present study revealed that YF3-5 interacted with CDK2, which has a vital role in $\mathrm{G}_{1}$ to $\mathrm{S}$ cell cycle phase transition (Table III). The three-dimensional structure demonstrated that compound YF3-5 may be embedded into the long and narrow hydrophobic pocket formed by Lys 89, Gln 85, Asp 86, Ile 10 and Leu 134 of CDK2 (Fig. 2D). The naphthalene ring residues of YF3-5 have hydrophobic interactions with the side chains of Lys 89 of the CDK2 and the carbonyl group and the hydroxyl group of YF3-5 may interact with the side chains of Gln 131 and Asp 86 of CDK2 (Fig. 2D). Retinoblastoma protein (Rb) is a tumor suppressor which negatively regulated cell cycle at the $\mathrm{G}_{1}$ phase (27). When cells transit from $\mathrm{G}_{1}$ to $\mathrm{S}$ phase, CDK2 phosphorylates $\mathrm{Rb}$, which results in the transcription factor E2F transcription factor 1 dissociating from $\mathrm{Rb}$ and entering the nucleus. Based on the docking results, the present study speculated that compound YF3-5 may attenuate the phosphorylation of Rb. To further elucidate the effects of YF3-5 against $\mathrm{Rb}$ phosphorylation, western blotting was performed to detect the expression level of phosphorylated $\mathrm{Rb}$. The results demonstrated that YF3-5 attenuated Rb phosphorylation (Fig. 2E).

Derivative YF3-5 induces ROS generation. ROS are chemically reactive molecules that serve an important role in cancer development $(28,29)$. It is well established that certain chemotherapeutic agents generate ROS in patients during cancer therapy (30). Therefore, it was of interest to investigate whether YF3-5 also induced ROS generation in A549 cells. YF3-5 was demonstrated to significantly induce intracellular ROS generation in A549 cells in a dose-dependent manner $(\mathrm{P}<0.001)$. At concentrations of 25,50 and $100 \mu \mathrm{M}, \mathrm{YF} 3-5$ increased intracellular ROS levels by 36.5, 60.5 and $92.2 \%$, respectively, compared with the vehicle control (Fig. 3).

Derivative YF3-5 induces apoptosis via generation of ROS in A549 lung cancer cells. Evidence has demonstrated that excessive ROS may induce apoptosis via the extrinsic and intrinsic 

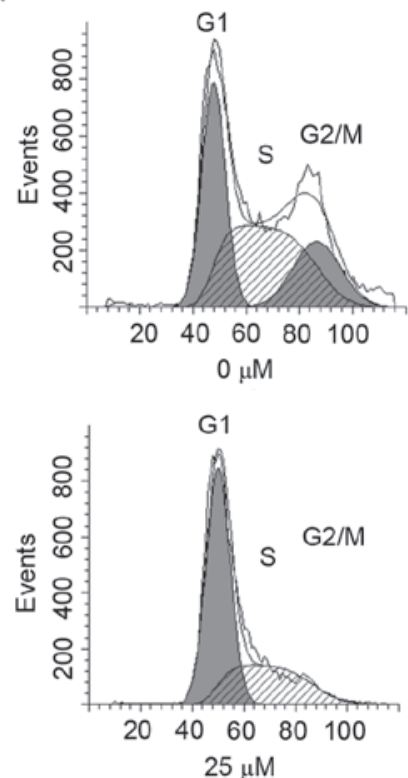

B

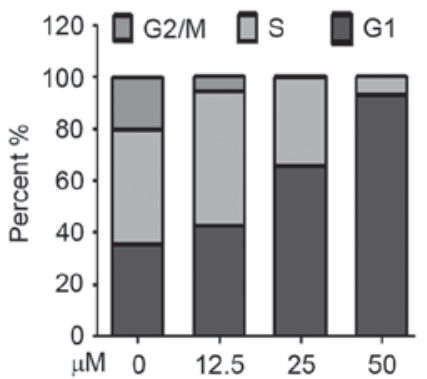

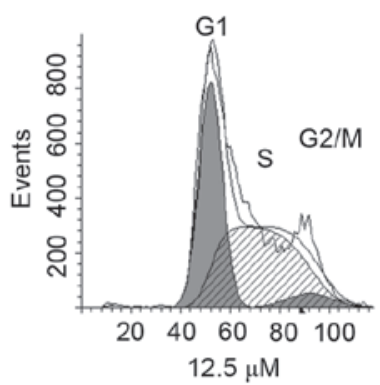

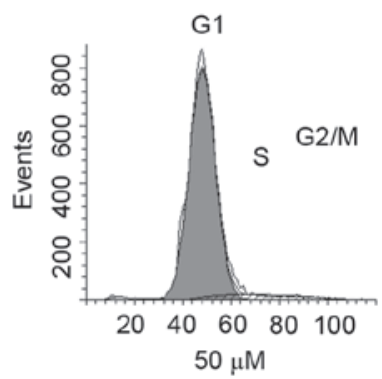

C

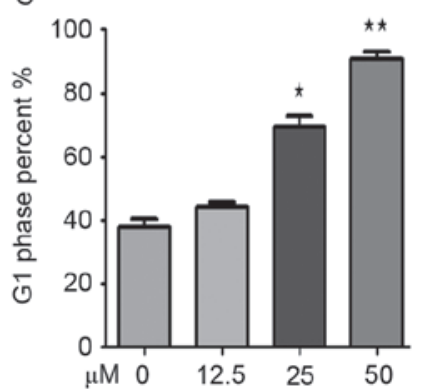

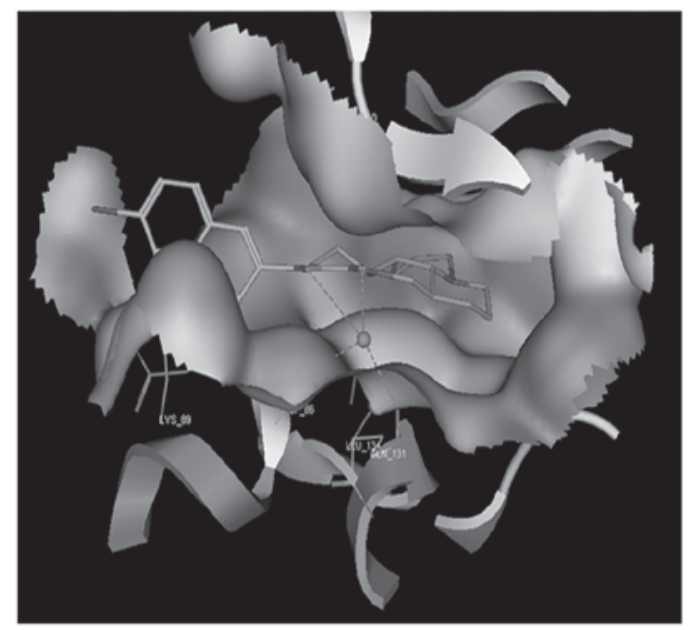

E

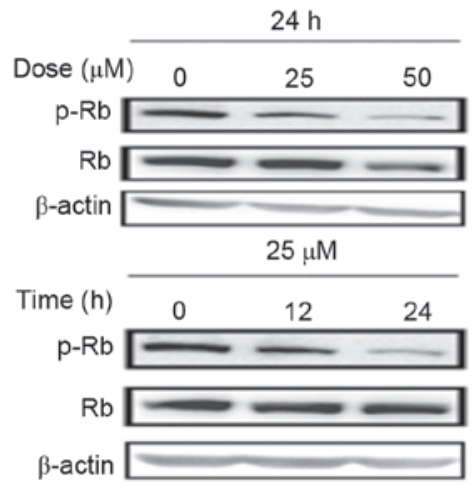

Figure 2. Compound YF3-5 arrests the cell cycle of A549 cells at the $\mathrm{G}_{1}$ phase. (A) A549 cells were treated with YF3-5 for $24 \mathrm{~h}$, stained with propidium iodide and analyzed by flow cytometry for cell cycle distribution. (B) Distribution of $G_{1}, S$ and $G_{2}$ cell cycle phases. (C) Analysis of cells in the $G_{1}$ phase of the cell cycle following treatment with YF3-5. (D) Molecular docking model of YF3-5 with CDK2. (E) Expression levels of phosphorylated retinoblastoma protein following a time course and numerous doses of YF3-5. Rb, retinoblastoma; $\mathrm{p}$, phosphorylated. ${ }^{*} \mathrm{P}<0.05,{ }^{* *} \mathrm{P}<0.01$ vs. control.

Table III. Molecular docking results of YF3-5 with proteins involved in $\mathrm{G}_{1}$ cell cycle phase regulation.

\begin{tabular}{lcccc}
\hline \multicolumn{2}{c}{ Target } & & & \multicolumn{2}{c}{ Docking score } \\
\cline { 5 - 6 } Protein & PDB ID & & Matrine & YF3-5 \\
\hline CDK2 & 2VV9 & & -10.398 & -15.864 \\
CDK4 & 2V9F & & -9.585 & -12.746 \\
CDK6 & 1JOW & & -7.312 & -9.41 \\
Cyclin D1 & 2W99 & & -9.389 & -13.767 \\
Cyclin E & 1W98 & & -7.369 & -7.563 \\
\hline
\end{tabular}

CDK, cyclin-dependent kinase; PDB ID, Research Collaboratory for Structural Bioinformatics Protein Data Bank identity.

pathways $(29,31)$. Subsequently, the present study detected whether YF3-5 induced apoptosis. Annexin V-FITC/7-AAD double staining assay was performed to investigate the effect of YF3-5 on apoptosis of A549 cells. As presented in Fig. 4A, following a 24-h treatment, YF3-5 significantly induced apoptosis in A549 cells in a dose-dependent manner $(\mathrm{P}<0.01)$.
At concentrations of 25,50 and $100 \mu \mathrm{M}$, YF3-5 induced apoptosis of A549 cells by 18.58, 34.03 and $49.05 \%$, respectively. To further elucidate the role of ROS in YF3-5 induced cell apoptosis, cells were co-treated with ROS scavenger $\mathrm{N}$-acetylcysteine (NAC) and YF3-5 and cell apoptosis assays were performed. The results demonstrated that exposure to NAC prevented YF3-5 induced apoptosis (Fig. 4B), suggesting a role of ROS in YF3-5 induced apoptosis.

\section{Discussion}

The mortality rate of lung cancer has declined with the emergence of tyrosine kinase inhibitors; however, problems remain, including drug resistance. There is an urgent requirement to develop new chemicals to improve lung cancer therapy. Matrine is a Chinese traditional liver protective drug that displays antitumor activity with moderate side effects. The present study used matrine as a starting point and synthesized five matrine derivatives. MTT results indicated that all the target compounds displayed improved anticancer effects compared with matrine. By analyzing the structure for relative activity, the present study revealed that the carbon-carbon double bond at $14^{\prime}$ of matrine skeleton is critical for improving the anticancer effects. In order to investigate a more in-depth 
A

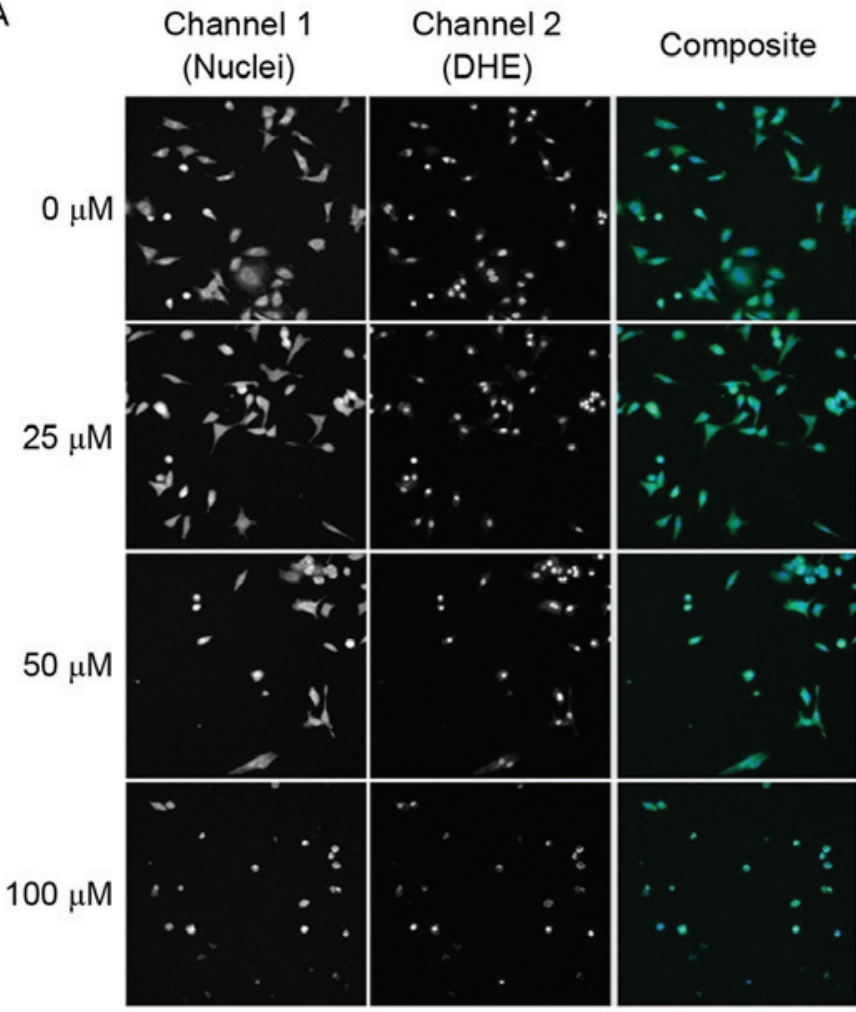

B

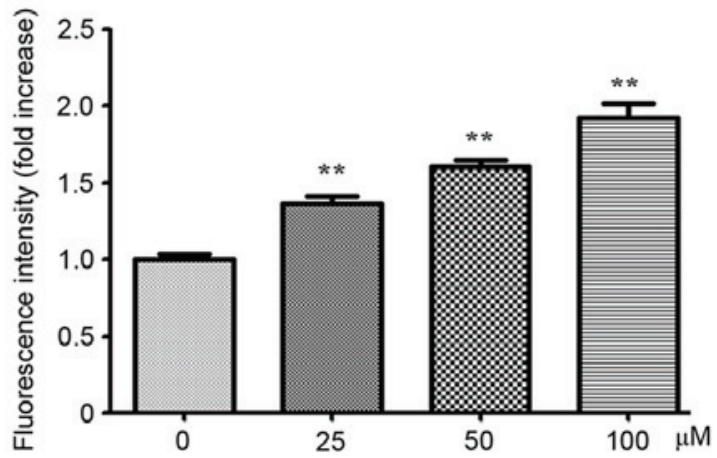

Figure 3. Compound YF3-5 induces reactive oxygen species generation in A549 cells. (A) A549 cells were treated with YF3-5 for 24 h and assessed using dihydroethidium and Hoechst dye staining (magnification, x100). (B) The statistical analysis of cell fluorescence intensity as determined by flow cytometry. DHE, dihydroethidium. ${ }^{* *} \mathrm{P}<0.01$ vs. control.
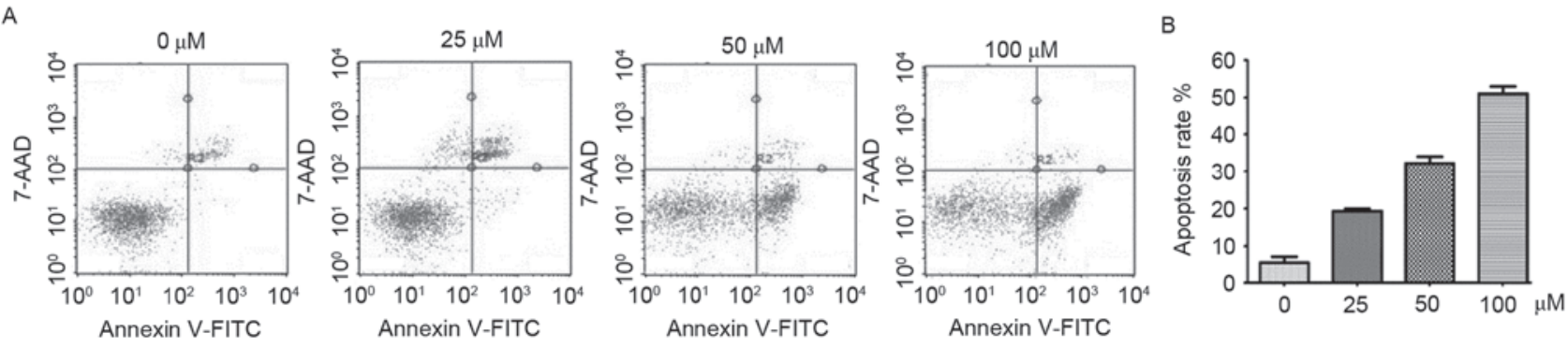

Figure 4. Compound YF3-5 induces apoptosis via the generation of reactive oxygen species in A549 cells. (A) A549 cells were treated with YF3-5 for $24 \mathrm{~h}$ and assessed by Annexin V/7-AAD staining and flow cytometry. (B) A549 cells were co-treated with N-acetylcysteine and YF3-5 for 24 h and assessed by Annexin V/7-AAD staining and flow cytometry. FITC, fluorescein isothiocyanate; 7-AAD, 7-aminoactinomycin D.

structure activity association, a series of matrine derivatives should be investigated in future studies.

Further investigation revealed that YF3-5 exhibited the most significant growth inhibition against human lung cancer cells by inducing apoptosis and $\mathrm{G}_{1}$ cell cycle arrest. Molecular docking results indicated that YF3-5 interacted with CDK2. Western blotting results revealed that treatment with YF3-5 induced phosphorylated $\mathrm{Rb}$ downregulation. These results suggested that YF3-5 may arrest the cell cycle at the $G_{1}$ phase by interacting with CDK2 and inhibiting the phosphorylation of Rb. Excessive ROS is also able to induce apoptosis $(29,31)$. The increased intracellular ROS expression levels induced by YF3-5 in A549 cells suggested that there may be an association between ROS generation and apoptosis induction mediated by YF3-5. The results of the present study demonstrated that YF3-5 induces cell apoptosis via the generation of ROS.
In conclusion, five matrine derivatives were synthesized and their anticancer effects were evaluated in four human cancer cell lines. YF3-5 displayed the strongest anticancer effects and induced $\mathrm{G}_{1}$ phase cell cycle arrest and ROS generation in A549 cells. Further results indicated that YF3-5 induced cell apoptosis via the generation of ROS. The present study provided further information for predicting the structural modifications of matrine derivatives to enable the synthesis of novel potent antitumor agents.

\section{Acknowledgements}

The present study was supported by the Natural Science Foundation of China (grant no. 21262005), the Natural Science Foundation of Guangxi (grant no. 2012GXNSFAA053158), the Scientific Research Foundation of Guangxi University 
(grant no. XJZ160924 and the Tennessee Center for Botanical Medicine Research.

\section{References}

1. McGuire S: World Cancer Report 2014. Geneva, Switzerland: World Health Organization, International Agency for Research on Cancer, WHO Press, 2015. Adv Nutr 7: 418-419, 2016.

2. Reck M, Popat S, Reinmuth N, De Ruysscher D, Kerr KM and Peters S; ESMO Guidelines Working Group: Metastatic non-small-cell lung cancer (NSCLC): ESMO clinical practice guidelines for diagnosis, treatment and follow-up. Ann Oncol 25 (Suppl 3): iii27-iii39, 2014.

3. Herbst RS, Heymach JV and Lippman SM: Lung cancer. N Engl J Med 359: 1367-1380, 2008.

4. Pao W, Miller VA, Politi KA, Riely GJ, Somwar R, Zakowski MF, Kris MG and Varmus H: Acquired resistance of lung adenocarcinomas to gefitinib or erlotinib is associated with a second mutation in the EGFR kinase domain. PLoS Med 2: e73, 2005.

5. Newman DJ and Cragg GM: Natural products as sources of new drugs over the last 25 years. J Nat Prod 70: 461-477, 2007.

6. Ai J, Gao HH, He SZ, Wang L, Luo DL and Yang BF: Effects of matrine, artemisinin, tetrandrine on cytosolic $[\mathrm{Ca} 2+] \mathrm{i}$ in guinea pig ventricular myocytes. Acta Pharmacol Sin 22: 512-515, 2001

7. Cheng H, Xia B, Zhang L, Zhou F, Zhang YX, Ye M, Hu ZG, Li J, Li J, Wang ZL, et al: Matrine improves 2,4,6-trinitrobenzene sulfonic acid-induced colitis in mice. Pharmacol Res 53 202-208, 2006

8. Li X, Chu W, Liu J, Xue X, Lu Y, Shan H and Yang B Antiarrhythmic properties of long-term treatment with matrine in arrhythmic rat induced by coronary ligation. Biol Pharm Bull 32: 1521-1526, 2009.

9. Long Y, Lin XT,Zeng KL and Zhang L: Efficacy of intramuscular matrine in the treatment of chronic hepatitis B. Hepatobiliary Pancreat Dis Int 3: 69-72, 2004.

10. Ma L, Wen S, Zhan Y, He Y, Liu X and Jiang J: Anticancer effects of the Chinese medicine matrine on murine hepatocellular carcinoma cells. Planta Med 74: 245-251, 2008.

11. Zhang P, Wang Z, Chong T and Ji Z: Matrine inhibits proliferation and induces apoptosis of the androgen-independent prostate cancer cell line PC-3. Mol Med Rep 5: 783-787, 2012.

12. Zhang Y, Zhang H, Yu P, Liu Q, Liu K, Duan H, Luan G, Yagasaki $\mathrm{K}$ and Zhang G: Effects of matrine against the growth of human lung cancer and hepatoma cells as well as lung cancer cell migration. Cytotechnology 59: 191-200, 2009.

13. Liu Y, Xu Y, Ji W, Li X, Sun B, Gao Q and Su C: Anti-tumor activities of matrine and oxymatrine: Literature review. Tumour Biol 35: 5111-5119, 2014.

14. Shao H, Yang B, Hu R and Wang Y: Matrine effectively inhibits the proliferation of breast cancer cells through a mechanism related to the NF- $\kappa B$ signaling pathway. Oncol Lett 6: 517-520, 2013.

15. Tan C, Qian X, Jia R, Wu M and Liang Z: Matrine induction of reactive oxygen species activates $\mathrm{p} 38$ leading to caspase-dependent cell apoptosis in non-small cell lung cancer cells. Oncol Rep 30: 2529-2535, 2013.
16. Niu H, Zhang Y, Wu B, Zhang Y, Jiang $\mathrm{H}$ and He P: Matrine induces the apoptosis of lung cancer cells through downregulation of inhibitor of apoptosis proteins and the Akt signaling pathway. Oncol Rep 32: 1087-1093, 2014.

17. Xiang J and Jiang Y: Antiepileptic potential of matrine via regulation the levels of gamma-aminobutyric acid and glutamic acid in the brain. Int J Mol Sci 14: 23751-23761, 2013.

18. Lu ZG, Li MH, Wang JS, Wei DD, Liu QW and Kong LY: Developmental toxicity and neurotoxicity of two matrine-type alkaloids, matrine and sophocarpine, in zebrafish (Danio rerio) embryos/larvae. Reprod toxicol 47: 33-41, 2014.

19. Chao F, Wang DE, Liu R, Tu Q, Liu JJ and Wang J: Synthesis, characterization and activity evaluation of matrinic acid derivatives as potential antiproliferative agents. Molecules 18: 5420-5433, 2013.

20. Du NN, Li X, Wang YP, Liu F, Liu YX, Li CX, Peng ZG, Gao LM, Jiang JD and Song DQ: Synthesis, structure-activity relationship and biological evaluation of novel N-substituted matrinic acid derivatives as host heat-stress cognate 70 (Hsc70) down-regulators. Bioorg Med Chem Lett 21: 4732-4735, 2011.

21. Yong J, Wu X and Lu C: Anticancer advances of matrine and its derivatives. Curr Pharm Des 21: 3673-3680, 2015.

22. Wang L, You Y, Wang S, Liu X, Liu B, Wang J, Lin X, Chen M, Liang $\mathrm{G}$ and Yang $\mathrm{H}$ : Synthesis, characterization and in vitro anti-tumor activities of matrine derivatives. Bioorg Med Chem Lett 22: 4100-4102, 2012.

23. Wu LC, Wen ZS, Qiu YT, Chen XQ, Chen HB, Wei MM, Liu Z, Jiang $S$ and Zhou GB: Largazole arrests cell cycle at G1 phase and triggers proteasomal degradation of E2F1 in lung cancer cells. Acs Med Chem Lett 4: 921-926, 2013

24. Wu L, Guo L, Liang Y, Liu X, Jiang L and Wang L: Curcumin suppresses stem-like traits of lung cancer cells via inhibiting the JAK2/STAT3 signaling pathway. Oncol Rep 34: 3311-3317, 2015.

25. Weinberg RA: The retinoblastoma protein and cell cycle control. Cell 81: 323-330, 1995.

26. Padilla F, Bhagirath N, Chen S, Chiao E, Goldstein DM, Hermann JC, Hsu J, Kennedy-Smith JJ, Kuglstatter A, Liao C, et al: Pyrrolopyrazines as selective spleen tyrosine kinase inhibitors. J Med Chem 56: 1677-1692, 2013.

27. Meng F, Qian J, Yue H, Li X and Xue K: SUMOylation of Rb enhances its binding with CDK2 and phosphorylation at early G1 phase. Cell Cycle 15: 1724-1732, 2016.

28. Gupta SC, Hevia D, Patchva S, Park B, Koh W and Aggarwal BB: Upsides and downsides of reactive oxygen species for cancer: The roles of reactive oxygen species in tumorigenesis, prevention, and therapy. Antioxid Redox Signal 16: 1295-1322, 2012.

29. Ozben T: Oxidative stress and apoptosis: Impact on cancer therapy. J Pharm Sci 96: 2181-2196, 2007.

30. Conklin KA: Chemotherapy-associated oxidative stress: Impact on chemotherapeutic effectiveness. Integr Cancer Ther 3: 294-300, 2004

31. Circu ML and Aw TY: Reactive oxygen species, cellular redox systems and apoptosis. Free Radic Biol Med 48: 749-762, 2010. 